\title{
THE SCOPE AND TYPES OF ENVIRONMENTAL HUMAN RIGHTS
}

\author{
Emrah AKYUZ ${ }^{1 * \mathbb{0}}$ \\ ${ }^{1}$ The University of Leeds, Sustainability Research Institute, Leeds, England \\ "Corresponding Author: emrahylsy@hotmail.com
}

\begin{abstract}
Environmental human rights (EHRs) have received greater worldwide attention over the years since first recognized by the 1972 Stockholm Declaration. Approximately 100 countries currently recognize and guarantee EHRs within their national constitutions. EHRs have been also used by such diverse groups as academics, social activists, international organizations, political parties, NGOs, etc. EHRs, however, are still a long way from being clear as a concept, or may at best be considered vague. This may be because different scholars have defined EHRs in different ways. In order to broaden and deepen our understanding of EHRs, this conceptual paper will attempt to explain the scope and types of EHRs through a critical analysis of the related literature by addressing the following research questions: (1) What is the scope of environmental human rights? and (2) What types of environmental human rights are there? It concludes with four main types of EHRs, including the right to environment, civil and political rights, and the constitutional and procedural rights that are the rights of individuals to preserve the environment in which they live.
\end{abstract}

Keywords: Human Rights, The Environment, Environmental Law, Environmental Human Rights

Received: 08.11.2017 Accepted: 06.12.2017

\section{INTRODUCTION}

Environmental human rights (EHRs) have been referenced by different groups, particularly scholars, activists, NGOs and international organizations (e.g. the United Nations) since their recognition at the international level by the 1972 Stockholm Declaration, which proclaimed that "Both aspects of man's environment, the natural and the man-made, are essential to his well-being and to the enjoyment of basic human rights the right to life itself'. This clearly implies that there is a direct connection between a safe environment and the enjoyment of human rights, which is the core argument of EHRs, but the term is still currently vague and unclear, as the literature does not provide any single, explicit definition, and which has thus been interpreted in different ways by different scholars depending on their values and priorities.

Another indeterminate point is related to the types of environmental human rights. It is still somewhat unclear to, or under debate by, scholars as to what types of environmental human rights there actually are, or should be, and how they are linked to each other. There is no recognition of environmental human rights by hard law at the international level, but there are many countries' constitutions, international soft law documents, and regional hard law declarations, which clearly recognize different types of environmental human rights. This raises the following question: what types of EHRs are there?

In light of the above discussions, this paper aims to achieve two fundamental goals. The first section attempts to determine the true scope of environmental human rights, or how we can define EHRs. The second section attempts to consider what types of environmental human rights exist at the international and national levels, and how these rights are connected with each other. By doing so, this paper intends to clarify the direct relationship between the environment and human rights.

\section{DEFINING "ENVIRONMENTAL HUMAN RIGHTS"}

Human rights are moral principles or norms, which are believed to belong to every person, and in whose exercise a government may not interfere. There are three overarching types of human rights norms: civil-political, socio-economic, and collective-developmental. 
Kotzé [1] describes the manifestation of human rights in an environmental context, and cites three common instances: (1) environmental rights; (2) environmental human rights; (3) human rights and the environment. He concludes that 'human rights and the environment' is the best definition, as the term allows for a decidedly holistic consideration of the relationship between all human rights.

The main reason for any conceptual uncertainty is the fact that EHRs do not have a rooted history [2], which means that they still need time to mature before they can be defined in a more definite way. It seems that there is no significant conceptual difference between these three terms, but it would be more appropriate to use the terms 'environmental human rights', as the first term implies that environmental rights refer to rights of the environment and the third term that human rights and environment-oriented rights refer to two different fields, when it is commonly accepted by scholars that the environment and human rights are directly related and cannot be discussed separately [3, 4]). In contrast, environmental human rights refer to rights of humans related to the environment, which is what they essentially are.

On the other hand, the scope of EHRs is still far from being clear $[3,5]$. This may be because various scholars have defined EHRs in many ways $[6,7]$. One commonality amongst these definitions is that environmental human rights are described as an expansion or reformulation of existing human rights and responsibilities in the specific context of environmental protection [4, 8]). According to this definition, the object of environmental human rights encompasses a reinterpretation of human rights laws; a new substantive right to be protected by state institutions; and the protection of the environment by state institutions and individuals.

Environmental human rights are, more specifically, not rights belonging to the environment [9], but the rights of humans to various environmental protections as they mainly derive from a reinterpretation of recognised human rights. The right to education, for example, does not seem directly relevant to environmental protection as it implies that education shall be equally accessible to all on the basis of merit, but as Boyle and Anderson [5] argue, it can be interpreted that education is a powerful means of informing people about environmental matters and informing people through the enjoyment of the right to education can result in better environmental decisions in favour of the natural world than uninformed ones. This approach links the right to education with environmental protection, which is defined as EHR. On this basis, EHRs depend on how people interpret human rights in relation to the environment.

On the other hand, saying that EHRs belong to people does not mean that humans can use the environment to satisfy their own needs as they wish; they have no direct right to an object (the environment), but to the action that allows them to protect their environment. EHRs make explicit reference to the protection of the environment itself, or to the protection of individuals from harm originating within the environment [10], which requires that a government has an obligation to protect those resources on behalf of its citizens and future generations. Therefore, it can be seen that the main goal of EHRs is to ensure the preservation of natural resources rather than the sovereignty of humans, the latter of which allows for the exploitation of the environment as humans see fit.

Hiskes [11] categorises EHRs as emergent rights, observing that they arise in response to threats to human dignity, a concept which underlies all "basic" human rights. It is unsurprising, therefore, that this definition and categorisation is agreed upon by many scholars [2, 12, 13]. However, it can be argued that this perspective is anthropocentric, in that it regards humankind as the central or most important actor [9], and ignores the inherent value of nature [14], as well as how humans affect or damage their habitat, impair ecosystems, and change the climate [15]. Indeed, it can be argued that regarding pollution as a threat to only human dignity makes the environment "guilty" and human beings "innocent", which is an extremely narrow approach. It is possible to take an alternative stance, which may reflect a more ecocentric perspective, according to which, in contrast to Hiskes [11]'s definition, environmental human rights are emergent in that they arise in response to threats to the environment caused by human activities that affect all subjects of that ecosystem, humans and non-humans $[16,17]$.

Lercher [18] develops a further and less common argument over the scope of EHRs. He states that environmental human rights against contamination are individual rights, rather than group rights. 
While individual rights are held by a single person, group rights are held by the group itself rather than by its individual members. The right to environment, constitutional rights, civil and political rights, and procedural rights are mainly held by individuals. The same argument is proposed by [19], that environment related rights are 'individual rights' that emerge as an extension, by way of interpretation, from other expressly recognised human rights - such as the right to life and health. It seems reasonable to categorise EHRs as individual rights due to the fact that they recognise the liberties of individuals and award them the right to life in a safe environment. Secondly, any disproportionate impact to the environment is, equally, an effect on an individual and his or her rights. Fukushima nuclear accident in 2011, for example, poses risks to residents' rights to life, health, property, and access to safe food and water in the region. In addition, traditionally, one of the main purposes of the doctrine of human rights has been to protect individuals from the power of groups, such as states [20]. Human rights are strongly associated with the concept of individualism. Thus, environmental human rights can be viewed as an effective tool for individuals to use against any state policy that threatens the environment on which they are physically dependent.

Conversely, the individualistic form of environmental human rights is not without exception. it would be arguably wrong to view environmental human rights as truly individual, as they can sometimes only be held by groups [11]. Arguments in favour of this view have been proposed by Boyle [21] who states that as environmental quality is a collective or solidarity right, environmental human rights can give communities, or "peoples", rather than individuals, the right to determine how the environment and natural resources should be protected and managed. It does not seem wrong that a safe environment is a collective purpose that people would like to achieve by exercising their environmental human rights, but this does not change the fact that environmental human rights that aim to protect the common home of people the environment - are held by all individuals rather than a group. Cullet [12] take thus argument further, suggesting that the right to environment is an individual right not only for existing people but that one must also consider the rights of future generations, whose interests must be similarly taken into account. As we cannot, he argues, identify whose individual members, then the right is given to a group, the so-called future generations, but he ignores the fact that the term addresses neither existing people nor future generations as rights holders. They are merely used to define the time period that rights holders live or will live. EHRs are, therefore, rights of individuals rather than groups.

\section{TYPES OF ENVIRONMENTAL HUMAN RIGHTS}

There is no specific right to environmental protection guaranteed by law at the international level [22]. However, this idea is not far away, and it is interesting that a distinct substantive right to environmental protection may be established as part of international law in the near future, as EHRs are increasingly being recognised by international, local and domestic law, such as the 1972 Stockholm Declaration and 1992 Rio Declaration $[4,23]$. The literature illustrates four main approaches to EHRs, which are not entirely mutually exclusive [24, 25]: first, mobilising civil and political rights to achieve environmental ends; secondly, reinterpretation of existing human rights (constitutional rights); thirdly, procedural rights, and lastly, creating new rights explicit to the environment [5], all of which largely remain an issue of philosophical debate.

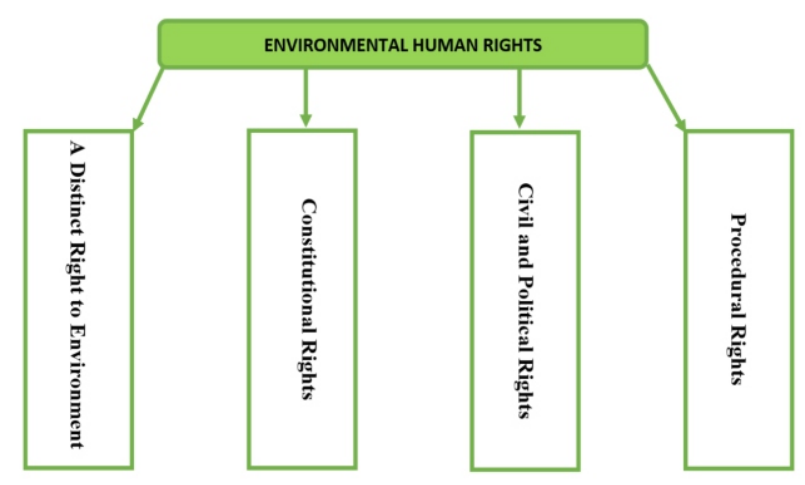

Figure 1. Types of Environmental Human Rights

\section{a) ADistinct Right to Environment}

A right to environment implies that a safe environment is one of the basic human rights to which all human beings are entitled because the environment is accepted as a basic human need; a provider of the air, water and food that are essential for human survival. That is, all people depend on the environment in which we live. 
A safe environment has been increasingly recognised as a human right by countries all over the world. At the national level, over 90 countries (such as Brazil, South Africa, Canada and India) guarantee a distinct right to environment in their own constitutions, obligating countries to preserve ecology, and giving citizens the opportunity to enjoy a healthy environment [3], but this does not mean that people fully realise this right. In terms of recognition, it appears that the right to a clean and healthy environment is assuming a higher degree of relevance. There is, however, no legally enforceable right to the environment at the international level. As the environment is everyone's home [25], and environmental issues such as major nuclear accidents have transboundary impacts on both people and the non-human world, the debate in the literature revolves around whether we should have a right to the environment that can be realised on a global scale $[5,12]$. As a right to the environment has both advantages and disadvantages, this can be considered either negatively or positively depending upon how a given scholar might perceive and weigh its weaknesses and strengths.

The discussion over a distinct right to environment is not without controversy, as there are both advantages and disadvantages. Advocates of the argument, for example Hayward [26] in the book "Constitutional Environmental Rights", argue that the right to an adequate environment is a genuine and ecologically sound right that should be provided in the constitution of any modern democratic state. The latest developments are in favour of Hayward [26]'s suggestion that over 90 countries, which can be found in their own constitution or the African Charter (which is a binding regional human rights document) guarantee the right to a safe and/or clean environment. Mann [27] takes a universal view and states that an internationally applied right to environment is needed to reduce the increasing number of environmental issues. Hancock [6] develops a more specific approach and suggests that the recognition of two particular rights, the right to an environment free from toxic pollution and ownership of natural resources, would protect human beings from harm to the environment. Thorme [28] agrees, but takes a highly pessimistic view that if this new right is not soon guaranteed, the Earth will ultimately become uninhabitable and people would disappear. Of course, recognition of such rights would bring some advantages to environmental protection. However, as Boyle and Anderson [5] argue, this does not mean that a right to environment is the only way to preserve both nature and human existence; well-protected civil and political human rights, for example, can also be effectively used to address environmental issues. As a rebuttal to this point, Thorme [28] ignores the fact that the planet, historically speaking, exists and was habitable for millions of years without new indeed, any -distinct right to environment. Additionally, procedural and civil and political rights can also be effectively used in environmental matters without recourse to a distinct right to environment. A right to environment is, therefore, not the only way to achieve environmental protection.

The main advantage of the right to environment is that a distinct right to environment, Gellers [4] argues, could be effectively used to address environmental issues affecting human life. The opposing view is also compelling. Pevato [29] discusses how if the ultimate goal of a right to environment is to give moral rights to concerned groups to raise only their concerns about environmental issues, then this can in fact be encouraged without any expressly recognised right to environment. Boyle [21] takes this argument further and claims that the right to expression, for example, is a far more effective way of enabling victims of environmental matters to raise their objections than a right to environment. A right to environment, however, may have more effective advantages in favour of nature. A rights-based approach to environmental protection would place states under the obligation to secure a clean environment for their citizens because this would demand positive state action to guarantee minimum standards towards protecting the right to environment [30]. Being in favour of the latter argument, Eacott [31] emphasizes on that recognition and enforcement of a right to environment would necessitate the creation and implementation of stronger, more comprehensive national and international laws of environmental protection.

Ziemer [32] takes the strong anthropocentric perspective that linking human rights to the environment creates a rights-based approach to environmental protection that places the people harmed by environmental degradation at the centre of the issue. Indeed, a right to environment may oblige states to conserve and protect nature 
because responsibility to protect human rights resides first and foremost with the states themselves. According to the International Law Commission, working on responsibility of states for internationally wrongful act and in conjunction with the implementation of the international Covenant on Economic, Social and Cultural rights, states have a threefold responsibility; (1) States must take positive action to facilitate the enjoyment of basic human rights; (2) States must refrain from interfering with or curtailing the enjoyment of human rights (3) States must protect individuals and groups against human rights abuses. This right becomes a legal weapon of concerned citizens to force their states to secure minimum standard to enjoy a right to environment; this clearly may serve in favour of environmental protection.

On the other hand, such an approach is not without problems, in particular with respect to implementation of such a right in a practical sense. A distinct substantive right to environment seems unenforceable [21, 33]. Some scholars, such as Boyle and Anderson [5], argue that a right to environment should be added to internationally recognised rights, as environmental issues are transboundary. They are partly correct insofar that major environmental issues such as nuclear accidents have worldwide implications. Their suggestion is, however, not convincing because opponents mainly argue that the practical implementation of a global substantive right to environment is highly challenging as it is not clear how the right to environment can be measured, protected, audited, and judged at the international level. This does not seem achievable as daily activities, directly or indirectly, contaminate the environment on an ongoing basis e.g., smoking, which is purported to cause 600,000 deaths amongst non-smokers annually [34]; using transportation which burns most of the world's petroleum [35]; the growing use of plastic products and increased global meat consumption. These are some regular, common activities performed by people in the modern world. If people have the right to a healthy environment, and if these and similar activities pollute nature, then unarguably the next step would be to discuss how to stop them. It seems utopian, but in practice the right to a healthy environment requires the need for action that protects it from any human activities that pollute nature. This is a theme taken up by Shelton [33], who states that, "no justiciable standards can be developed to enforce the right, because of the inherent variability of environmental conditions". Thus, the boundaries of the right to a healthy environment are undefined and vague, while its actual implementation appears to be challenging and complex at an international level. This may be the main reason why there is still no distinct right to a healthy environment at the international level.

Secondly, it is argued that cultural relativism would be an obstacle to achieve a distinct right to environment at the international level. Handl [36] argues the right to environment on epistemological grounds, claiming that cultural relativism would be an obstacle to the implementation of substantive components of the expansive right to environment at the international level. The notion of cultural relativism was developed by Franz Boas in 1911, which emphasises that no moral principles can be formed that will apply to all cultures because human rights are themselves culturally dependent [37]. Donnelly [38] claims that cultural relativism is an undeniable fact; that is, culture is an important source of the validity of a moral human right. The opposing viewpoint is universalism, which regards human rights as a single universal concept. The modern system of the international human rights framework is indeed based on the concept of universalism, which means that human rights are an entitlement of all human beings regardless of their culture, religion, age, gender, etc. [39], but this is still under debate. Zechenter [40], for example, argues that universalism is merely an uncritical, ethnocentric Western conspiracy designed to undermine non-Western cultures. Similarly, Perusek [41] defines universalism as Western traditionalism that ignores the diversity of cultures worldwide. It appears true that the UDHR Universal Declaration, for example, is rooted in political landmarks in Western history, such as the Magna Carta of the United Kingdom (1215), the French Revolution (1789) and the American Bill of Rights (1791). Nevertheless, the right to environment is not recognised by the UDHR [42]. Additionally, the first binding regional document recognising a right to environment is the African Charter; the origins of EHRs may not be rooted purely in Western culture.

\section{b) Reinterpretation of Existing Human Rights: Constitutional Rights}

Some scholars argue that EHRs should be 
added to internationally recognised human rights to protect human rights, wellbeing and dignity from environmental harm. While Thorme [28] suggests the recognition of a right to a healthy environment, Hancock [6] offers the right to an environment free from toxic pollution and ownership of natural resources as a solution to the issue. As Woods [25] points out, the key argument is not recognition of these rights as they are already implicit in internationally recognised human rights. On the basis of this argument, there is no need for separate EHRs because wellestablished and legally enforceable human rights require a safe environment. They are also referred to as the constitutional rights to a healthy/clean environment [43].

There are a great number of supporters of this argument. Olawuyi [44] and Alfredsson and Ovsiouk [45], for example, argue that the realisation of certain well-established substantive human rights, such as those relating to life, food, health, is inherently dependent on the successful management of the environment. Nickel [46] explains the reasoning behind this argument and states that it is not possible to protect human rights without a safe environment because the most severe effects of pollution, toxic wastes, and inadequately processed sewage result in the sicknesses and deaths that undermine recognised rights. This is a relatively narrow perspective because some environmental issues - particularly nuclear accidents - significantly affect the lives of individuals. Pathak [47] applies basic needs theory in that the lack of good quality air, water and food as provided by the environment is the greatest obstacle to the fulfilment of the right to life and health. He also acknowledges the trap that it would be narrow-minded to limit any impact to the environment to purely those of life and health, as any such impact would also pose risks to the right to food and water.

It seems that this approach does not attempt to set out any new vision for the relationship between the two, but instead merely touches on the interconnection between the protection of the environment and the fulfilment of human rights, which have in any case been recognised since the 1972 Stockholm Declaration. The advantage of this argument, however, is, as Thorme [28] argues, that it demands positive state action in order to guarantee minimum environmental standards for human rights because it is the responsibility of states to take essential steps to protect constitutional rights such as the right to life. For example, Article 27b of the Constitution of Uganda states that: "The State shall ensure that ... all Ugandans enjoy rights and opportunities and access to education, health services, clean and safe water, decent shelter, adequate clothing, food, security and pension and retirements benefits" [43]. In this sense, environmental protection becomes a legal, rather than moral, obligation for states in order to protect constitutional human rights such as the right to water, food, health, property, etc. Similarly, Ziemer [32] argues that linking human rights to environment issues creates a rights-based approach to environmental protection that enables citizens to force their governments to preserve nature in order to realise enjoyment of recognised substantive human rights. If enforcement bodies [5] explicitly recognise such a relationship, then environmental criteria may be directly incorporated into the monitoring and enforcement of human rights. His argument seems correct in that this may arguably depend on values or environmental awareness of judges who may, or may not, link the two. In other words, there is no guarantee that enforcement bodies may not link the two, although others maybe will. Environmental human rights, therefore, are implicit to the constitutional rights that states are obliged to protect and provide minimum standards for environment, which does not pose an obstacle to the enjoyment of substantive human rights.

\section{c) Civil and Political Rights}

Whilst less common than the other approaches mentioned above, a few scholars claim that we have internationally well-established civil and political rights that can be strong vehicles for addressing environmental issues and that, in particular, they can foster an environmentallyfriendly political order at the domestic level [8, 22]. Civil and political rights, very briefly, can be defined as a class of human rights that protect individuals' freedoms from infringement by governments, social organisations, and other private individuals [48, 49]. They restrict the powers of central or local governments regarding actions that might affect individuals and their rights/liberties [50]. The International Covenant on Civil and Political Rights (ICCPR) is the core of the legally binding human rights treaty, providing a range of protections for civil and political rights at the international level, and 
is signed by 168 state parties [51]. Civil and political rights may vary from country to country, but the most common ones include freedom to worship, freedom of thought and expression, the right to vote, to take part in political life, and to have freedom of assembly and association [52].

It seems that civil and political rights are not directly linked with EHRs or environmental protection, but as Boyle and Anderson [5] argue, the realisation of such rights, particularly the right to expression, association and political participation, may enable concerned citizens to raise their objection to environmental harm and policies. These rights are not limited to individuals; they may also include legal personality or organisations. In this sense, Boyle [21] points out that their importance lies in their ability to give individuals, groups and nongovernmental organisations (NGOs), who are affected or threatened by environmental degradation, the opportunity to voice their objections. Controversially, Dias [53] touches upon an important issue through his claim that environmental protection via civil and political rights is not an easy process in practice because they may be vulnerable to governmental control, which means autocratic regimes would be an obstacle to the enjoyment of civil and political rights. Indeed, this issue might be considered more obvious in Middle Eastern, Latin American, and Asian countries which suffer from the lack of a healthy democracy, and well-developed and protected human rights [54], which ultimately results in autocratic regimes representing the greatest obstacle to the enjoyment of civil and political rights for the protection of the environment. Sachs [55] underlines another issue, in that civil and political rights cannot be effective in isolation because they can only create a duty to refrain from certain actions that are harmful to the environment. He implies that they are negative rights that usually oblige inaction on the part of the government. However, arguably, he falls into the trap of ignoring the fact that, sometimes, the effective enjoyment of certain civil and political rights may also force government to take action through the allocation of appropriate resources; for example, if the majority of citizens exercise their rights against NPPs, then they may force their governments to invest in renewable energy sources instead.

\section{d) Procedural Rights}

Procedural rights are based on three pillars: a right to information, a right to participation, and a right to access to justice. The 1992 Rio Declaration is the first international document that defines and fosters procedural rights which have been commonly conceived as being more transparent, inclusive, and accountable in the decision-making progress concerning matters affecting the environment that people are dependent upon. Principle 10 states that:

"Environmental issues are best handled with the participation of all concerned citizens, at the relevant level. At the national level, each individual shall have appropriate access to information concerning the environment that is held by public authorities, including information on hazardous materials and activities in their communities, and the opportunity to participate in decision-making processes. States shall facilitate and encourage public awareness and participation by making information widely available. Effective access to judicial and administrative proceedings, including redress and remedy, shall be provided"

Anton and Shelton [3] argues that each procedural right is a piece of the puzzle in building good environmental governance. That is, they are closely integrated with each other and may be ineffective in the absence of one or another of them; for example, if public authorities do not proactively make environmental information available, meaning that members of the public cannot exercise their right to information, the right to participation in decision-making processes may be rendered meaningless or ineffective, as uninformed or ill-informed citizens are not able to reflect on their thoughts in the absence of relevant information, and poor knowledge may affect people's decisions and awareness in a negative way [56]. From this perspective, it is reasonable to assert that the right to information is a prerequisite for effective participation. Similarly, access to justice is, inter alia, required to enforce the rights to access to information and participation [57].

Procedural rights, including participation in decision-making processes, access to information and access to justice are essentially recognised as civil and political rights by many international human rights documents. Article 25 of International Covenant on Civil and Political Rights, which is a multilateral treaty adopted by the United Nations General Assembly in 1966, states that: "Every citizen shall have the right and the opportunity to take part in the conduct of 
public affairs, directly or through freely chosen representatives." Similarly, article 21 of the Universal Declaration of Human Rights, which is the first time that countries agreed on a comprehensive statement of inalienable human rights, states that: "Everyone has the right to take part in the government of his country, directly or through freely chosen representatives." Not only public participation but also access to information can be categorised as one of civil and political human rights. It is generally accepted that access to information is necessary for the realization of the basic rights to freedom of opinion and expression; and public participation in governmental activities that are guaranteed in the United Nations Declaration on Human Rights. Article 13 of American Convention on Human Rights, which an international human rights instrument adopted in 1969, states that: "Everyone has the right to freedom of thought and expression. This right includes freedom to seek, receive, and impart information and ideas of all kinds, regardless of frontiers, either orally, in writing, in print, in the form of art, or through any other medium of one's choice.". Similarly, access to justice is recognised by many constitutions including Brazil, Bolivia, Portugal, Kenya, and so on, as a fundamental right. Article 42 of the Constitution of Russia states that: "Everyone shall have the right to ... compensation for the damage caused to his or her health or property by ecological violations" [56]. Their adoption into environmental governance had been achieved by principle 10 of the 1992 Rio Declaration, which states that: "Environmental issues are best handled with the participation of all concerned citizens ...... each individual shall have appropriate access to information concerning the environment." Procedural rights are, therefore, human rights recognised by international treaties and national constitutionals.

Why are procedural rights important for environmental protection? Boyle and Anderson [5] states that procedural rights promise environmental protection essentially by way of democratic environmental governance because, as May [56] explains, they promote democratisation and concomitant rights to assemble, speak, and participate in governance. Lynn [57] highlights the importance of public participation in that ensuring public involvement is essential to defining the parameters of a problem, framing the questions that need to be answered, deciding what information needs to be generated, interpreting such information, and choosing among available public policy options and means of implementation. This results in, as Sax [58] argues, the most environmentally friendly decisions possible as the process enables concerned citizens to choose "what quality and quantity of natural resources we should be entitled to access". This remains a quite optimistic perspective, in that enjoyment of procedural rights may not always guarantee the most rational decisions in favour of the environment; ultimately, people may not perceive environmental benefits or benefit and cost of the decisions in a same way. For example, advocates of nuclear energy claim that NPPs are an environmentally friendly energy source due to negligible gas emissions in comparison to fossil fuel-fired power stations. In contrast, opponents claim that NPPs are the most dangerous form energy to the environment due to the generation of radioactive wastes. So, the question remains: what is the most environmentally-friendly decision for NPPs? Each decision can be disappointing or not environmentally-friendly for some groups, as depends on their particular set of values.

On the other hand, limiting participatory governance to only concerned citizens seem an overly narrow practice. As Rose-Ackerman and Halpaap [59] point out, a decision in participatory governance is taken by such diverse groups as citizens, NGOs, scientists and other experts. There is no lack in the controversy that surrounds this in particular due to issues of time management. If participants have diverse social, political and environmental goals or different environmental values, this would represent a considerable obstacle to making any rapid or immediate decisions on any given matter.

However, some environmental issues, such as nuclear accidents, require immediate action and quick response as radioactive contamination poses such a serious - indeed, potentially fatal - risk to human health. Another issue is that there is no fixed rule as to what extent, or at what level, the public should ideally be engaged. Public participation in each single decision can be financially costly and highly time consuming [57].

Another advantage of procedural rights is, Gellers and Jeffords [60] argue, that marginalised groups who face an unequal burden of environmental harm can forward their environmental and health concerns to other 
people, organisations, and officials through active participation in environmental decision-making, which is taken such as diverse groups, and indeed this can act as an early warning system for public concerns. The literature commonly addresses the fact that procedural rights enable even the most disadvantaged groups within a society, who face distributive justice issues, to give voice to their concerns, to effectively monitor and hold their government to account, and to enter into informed dialogue regarding public authority decisions [61, 62]. In a similar sense, Lawrence et al. [63] states that procedural rights are a useful vehicle to reduce dissatisfaction with unfavourable decisions that result in distributive injustice. Indeed, distributive injustice is a visible moral issue in environmental matters, particularly nuclear incidents. All citizens benefit from the electricity generated by nuclear stations equally but those who live close to the station are always more vulnerable to a potential nuclear accident than people who live further away. They may, however, stay insufficient in addressing ecological and intergenerational justice issues as procedural rights do not guarantee any right to the non-human world and future generations that might also be at risk from the long-term consequences of nuclear accidents.

\section{CONCLUSION}

This paper has focussed on the scope and types of environmental human rights through an analysis of the related literature. Firstly, as has been reported above, environmental human rights are based on the connection between the environment and human rights. This relationship can be conceived in two different ways: the first, and most common, is that the environment has been considered a precondition of the realisation and enjoyment of human rights since the 1972 Stockholm Declaration; the second, and more recent, is that human rights are accepted as an effective means of addressing environmental issues that people suffer/witness, thus forcing public authorities to implement more sustainable environmental policies and to affect environmental decisions in favour of nature. From this perspective, it seems reasonable to say that EHRs are not the right to the environment for its own sake; rather, they are fundamental human rights of individuals (like the right to life and health) to environmental protection.

The second conclusion is that EHRs are of four different types, which include the right to the environment, constitutional rights, civil and political rights, and procedural rights. The right to the environment, which is guaranteed by more than 100 countries worldwide, implies that people have a fundamental right to a clean/safe/healthy environment. The second argument is that there is no need for a separate right to the environment because this is already a prerequisite of wellestablished and recognised human rights, such as the right to life and health; these are called constitutional EHRs. The third argument states that civil and political rights, such as the right to expression and protest, enable citizens to affect decision-making processes in an eco-friendly way. Lastly, procedural rights, which include the right to participation in decision-making processes, the right to have access to information, and the right to justice, can be an effective means of achieving the environmental protection that is essential to the realisation of human rights. These three types are, however, not alternatives to each other; rather, they are pieces of a puzzle whose ultimate aim is one of a truly safe environment.

\section{REFERENCES}

[1] Kotzé, L. J. (2014). Human rights and the environment in the Anthropocene. The Anthropocene Review, 1(3), 252-275.

[2] Nagaraja, V. (2015). Human Rights and Environment. Asia Pacific Journal of Management \& Entrepreneurship Research, 4(1), 162-173.

[3] Anton, D. K., \& Shelton, D. L. (2011). Environmental protection and human rights. Cambridge University Press.

[4] Gellers, J. (2012). Greening constitutions with environmental rights: Testing the isomorphism thesis. Review of policy research, 29(4), 523-543.

[5] Boyle, A. E., \& Anderson, M. R. (1996). Human rights approaches to environmental protection. Clarendon Press.

[6] Hancock, Jan (2003). Environmental human rights: Power, ethics, and law. Ashgate Publishing, Ltd.

[7] Jeffords, C. (2013). Constitutional environmental human rights: A descriptive analysis of 142 national constitutions. The State of Economic and Social Human Rights: A Global Overview. 
[8] Bosek, J. K. (2014). Implementing environmental rights in Kenya's new constitutional order: Prospects and potential challenges. African Human Rights Law Journal, 14(2), 489-508.

[9] Hargrove, E. C. (1992). Weak anthropocentric intrinsic value. The Monist, 75(2), 183-207.

[10] Miller, C. (2012). Environmental rights: Critical perspectives. Routledge.

[11] Hiskes, R. P. (2005). The right to a green future: Human rights, environmentalism, and intergenerational justice. Human Rights Quarterly, 27(4), 1346-1364.

[12] Cullet, P. (1995). Definition of an environmental right in a human rights context. Neth. Q. Hum. Rts., 13, 25.

[13] Pathak, P. (2014). Human Rights Approach to Environmental Protection. OIDA International Journal of Sustainable Development, 7(01), 17-24.

[14] Colon-Rios, J. (2015). Comment: The rights of nature and the new Latin American constitutionalism. New Zealand Journal of Public and International Law, 13(1), 107.

[15] Kudeikina, I. (2014). The understanding of co-owners' rights in the context of the genesis of environmental rights. In SHS Web of Conferences (Vol. 10, p. 00019). EDP Sciences.

[16] Singer, P. (1979). Not for humans only: the place of nonhumans in environmental issues. Ethics and Problems of the 21st Century, 191-206.

[17] Gaard, G. (1993). Living interconnections with animals and nature. Ecofeminism: Women, animals, nature, 1-12.

[18] Lercher, A. (2007). Are there any Environmental Rights?. Environmental Values, 16(3), 355-368.

[19] Francioni, F. (2010). International human rights in an environmental horizon. European Journal of International Law, 21(1), 41-55.

[20] Jones, P. (1999). Human rights, group rights, and peoples' rights. Human Rights Quarterly, 21(1), 80-107.

[21] Boyle, A. (2006). Human Rights or Environmental Rights-A Reassessment. Fordham Envtl. L. Rev., 18, 471.

[22] Feris, L. (2008). Constitutional environmental rights: an under-utilised resource. S. Afr. J. on Hum. Rts., 24, 29.

[23] Pedersen, O. W. (2008). European Environmental Human Rights and
Environmental Rights: A Long Time Coming?. Georgetown International Environmental Law Review, 21(1).

[24] Ellis, G. (2006). Do Environmental Rights Have A Role In The British Planning System? (Doctoral Dissertation, The Univ. Of Wales College OfCardiff(United Kingdom).

[25] Woods, K. (2006). What does the language of human rights bring to campaigns for environmental justice?. Environmental Politics, 15(4), 572-591.

[26] Hayward, T. (2005). Constitutional environmental rights. Oxford University Press.

[27] Mann, H. (1992). The Rio Declaration. In Proceedings of the Annual Meeting (American Society of International Law) (pp. 405-414). The American Society of International Law.

[28] Thorme, M. (1990). Establishing environment as a human right. Denv. J. Int'1 L. \& Pol'y, 19, 301.

[29] Pevato, P. M. (1998). International law and the right to environment: encouraging environmental cooperation via the international protection of human rights (Doctoral dissertation, London School of Economics and Political Science (University of London).

[30] Madebwe, T. (2015). A rights-based approach to environmental protection: The Zimbabwean experience. African Human Rights Law Journal, 15(1), 110-128.

[31] Eacott, E. (2001). Clean and Healthy Environment: The Barriers and Limitations of This Emerging Human Right, A. Dalhousie J. Legal Stud., 10, 74.

[32] Ziemer, L. S. (2001). Application in Tibet of the Principles on Human Rights and the Environment. Harv. Hum. Rts. J., 14, 233.

[33] Shelton, D. (2008). Environmental rights and Brazil's obligations in the Inter-American human rights system. Geo. Wash. Int'l L. Rev., 40, 733 .

[34] World Health Organization.(2017). Secondhand smoke. Retrieved from http://www.who.int/en/

[35] Keles, R., Hamamc1, C., \& Çoban, A. (2012). Çevre Politikası. Ankara: İmge Publishing House.

[36] Handl, G. (1992). Human rights and protection of the environment: a mildly revisionist view. Human rights approaches 
to environmental protection. Oxford University Press, Oxford, 117-142.

[37] Stocking, G. W. (1966). Franz Boas and the culture concept in historical perspective. American Anthropologist, 68(4), 867-882.

[38] Donnelly, J. (1984). Cultural relativism and universal human rights. Human Rights Quarterly, 6(4), 400-419.

[39] Renteln, A. D. (2013). International human rights: universalism versus relativism. Quid Pro Books.

[40] Zechenter, E. M. (1997). In the name of culture: Cultural relativism and the abuse of the individual. Journal of Anthropological Research, 319-347.

[41] Perusek, D. (2007). Grounding cultural relativism. Anthropological Quarterly, 80(3), 821-836.

[42] Ng, T. (2011). Environmental Rights: Progressive Development or Obfuscation of International Human Rights Law. Original Law Review 7(3), 72-104.

[43] Ebeku, K. S. (2007). Constitutional right to a healthy environment and human rights approaches to environmental protection in Nigeria: Gbemre v. Shell revisited. Review of European Community \& International Environmental Law, 16(3), 312-320.

[44] Olawuyi, D. S. (2014). Recognizing the Intersections between Human Rights and the Environment in Legal Education and Training. Asian Journal of Legal Education, 1(2), 103-113.

[45] Alfredsson, G., \& Ovsiouk, A. (1991). Human Rights and the Environment. Nordic J. Int'1 L., 60, 19.

[46] Nickel, J. W. (1993). Human Right to a Safe Environment: Philosophical Perspectives on Its Scope and Justification, The. Yale J. Int'l L., 18, 281.

[47] Pathak, R. S. (1992). The human rights system as a conceptual framework for environmental law. United Nations University.

[48] Faiz, P. M. (2016). The Protection of Civil and Political Rights by the Constitutional Court of Indonesia. Browser Download This Paper.

[49] Byrne, I. (2004). The Importance of Economic, Social and Cultural Rights in Guaranteeing Civil and Political Rights within the Euro-Mediterranean Partnership. Mediterranean Politics, 9(3), 344-367.
[50] Keith, L. C. (1999). The United Nations International Covenant on Civil and Political Rights: Does it make a difference in human rights behavior?. Journal of Peace Research, 36(1), 95-118. 